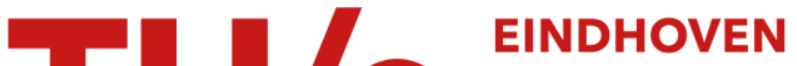

\section{Optical and electronic properties of GaAs-based structures with columnar quantum dots}

\section{Citation for published version (APA):}

Motyka, M., Sek, G., Ryczko, K., Andrzejewski, J., Misiewicz, J., Li, L., Fiore, A., \& Patriarche, G. (2007). Optical and electronic properties of GaAs-based structures with columnar quantum dots. Applied Physics Letters, 9O(18), 181933-1/3. [181933]. https://doi.org/10.1063/1.2736287

DOI:

$10.1063 / 1.2736287$

Document status and date:

Published: 01/01/2007

\section{Document Version:}

Publisher's PDF, also known as Version of Record (includes final page, issue and volume numbers)

\section{Please check the document version of this publication:}

- A submitted manuscript is the version of the article upon submission and before peer-review. There can be important differences between the submitted version and the official published version of record. People interested in the research are advised to contact the author for the final version of the publication, or visit the $\mathrm{DOI}$ to the publisher's website.

- The final author version and the galley proof are versions of the publication after peer review.

- The final published version features the final layout of the paper including the volume, issue and page numbers.

Link to publication

\section{General rights}

Copyright and moral rights for the publications made accessible in the public portal are retained by the authors and/or other copyright owners and it is a condition of accessing publications that users recognise and abide by the legal requirements associated with these rights.

- Users may download and print one copy of any publication from the public portal for the purpose of private study or research.

- You may not further distribute the material or use it for any profit-making activity or commercial gain

- You may freely distribute the URL identifying the publication in the public portal.

If the publication is distributed under the terms of Article 25fa of the Dutch Copyright Act, indicated by the "Taverne" license above, please follow below link for the End User Agreement:

www.tue.nl/taverne

Take down policy

If you believe that this document breaches copyright please contact us at:

openaccess@tue.nl

providing details and we will investigate your claim. 


\title{
Optical and electronic properties of GaAs-based structures with columnar quantum dots
}

\author{
M. Motyka, ${ }^{\text {a) }}$ G. Sęk, K. Ryczko, J. Andrzejewski, and J. Misiewicz \\ Institute of Physics, Wroctaw University of Technology, Wybrzeze Wyspianskiego 27, \\ 50-370 Wroctaw, Poland \\ L. H. Li and A. Fiore \\ Ecole Polytechnique Fédérale de Lausanne, Institute of Quantum Electronics and Photonics, \\ Station 3, CH-1015 Lausanne, Switzerland \\ G. Patriarche \\ Laboratoire de Photonique et de Nanostrucures, Centre National de la Recherche Scientifique, \\ Route de Nozay, F-91460 Marcoussis, France
}

(Received 19 March 2007; accepted 11 April 2007; published online 4 May 2007)

\begin{abstract}
The electronic properties of a structure with columnar quantum dots obtained by close stacking of InAs submonolayers have been investigated by contactless electroreflectance (CER) and photoluminescence. These dots have an almost ideally rectangular cross section and uniform composition, which is promising for polarization independent gain. After energy level calculations in the effective mass approximation using composition profiles obtained from cross-sectional transmission electron microscopy the part of the CER spectrum related to the two-dimensional surrounding layer has been explained and single heavy-hole-like and light-hole-like transitions related to the columnar dots identified, due to a single electron state confined in a shallow in-plane potential. () 2007 American Institute of Physics. [DOI: 10.1063/1.2736287]
\end{abstract}

There has been great interest in the optical properties of self-assembled GaAs-based quantum dot (QD) structures during the last few years due to their broad potential application in optoelectronic devices. For example, QD lasers covering spectrally the optical fiber telecommunication range $(1.3-1.55 \mu \mathrm{m})$ show some improved characteristics, such as low threshold current and its temperature insensitivity expressed by high $T_{0}$ values, both due to three-dimensional carrier confinement and deltalike density of states. ${ }^{1,2}$ On the other hand, large inhomogeneity of the ensemble of dots can be utilized in the applications requiring broad gain spectrum, such as tunable lasers, superluminescent diodes, and semiconductor optical amplifiers (SOAs). The quantum dot SOAs are a class of promising optical devices with expected properties such as high saturation power, multiwavelength operation, and high speed response. ${ }^{3}$ However, in this case the control of the polarization of the emitted light and obtaining QD-based polarization independent amplifiers has become a main challenge because of the strongly TE-polarized gain, ${ }^{4}$ related to their geometry and strain distribution One of the ways to overcome this limitation is the shape engineering of the QD material and hence modifying the polarization properties of the optical gain function. It has been proposed to use "columnar QDs," grown by close stacking of InAs submonolayers on top on a seed QD, to obtain a significantly increased height/base width ratio. ${ }^{4-6}$ Almost polarization independent modal gain and loss were recently demonstrated. ${ }^{7}$ In this letter, we focus on the understanding of the optical transitions and the electronic structure of such uncommon QD system, which has remained largely unexplored so far. Among the open questions are, for instance, the real content profile within the dots and hence nature of the confinement

${ }^{a)}$ Electronic mail: marcin.motyka@pwr.wroc.pl potential, the number of confined states in these relatively large dots, the character of the surrounding two-dimensional (2D) layer of the whole stack (which replaces the ordinary wetting layer (WL) in standard Stranski-Krastanow QDs) and its influence on the dot properties, etc. Using the advantages of modulation spectroscopy in the form of contactless electroreflectance (CER), as its absorptionlike character and high sensitivity to optical transitions including also the QDrelated ones, ${ }^{8,9}$ it has been possible to investigate the electronic structure in detail. In order to support the interpretation of the CER spectra a standard high-excitation photoluminescence has been measured and effective mass calculations of the energy levels for the dots and the 2D layer have been performed based on the structure parameters determined from the cross-sectional transmission electron microscopy (TEM) images and composition profiles.

The sample investigated here was grown by solid source molecular beam epitaxy by close stacking of InAs and GaAs layers on (001) oriented GaAs substrate. The active part has been preceded by a GaAs buffer and then capped with $100 \mathrm{~nm}$ GaAs cap. The columnar dots have been obtained by submonolayer stacking, i.e., the repeated deposition of 0.62 ML of InAs and $3 \mathrm{ML}$ of GaAs on top of a layer of a standard self-assembled InAs/GaAs QDs formed by depositing 1.8 ML of InAs. The stack of 16 layers (InAs/GaAs pair repetitions) gave structures with columnar dots, as shown in the TEM image in Fig. 1. However, the plane-view TEM (not presented here) has shown that the base of the columns is rather rhombus in shape, with diagonals alongs the [110] and $[1-10]$ directions and their length ratio of 1.22 . The shape of the cross section taken along the [110] direction (i.e., shorter of the diagonals) gives almost ideal 20 $\times 20 \mathrm{~nm}^{2}$ square. Figure 1 has also allowed determination of the thickness of the $2 \mathrm{D}$ layer surrounding the dots in plane (approximately $20 \mathrm{~nm}$ ) and the composition profiles across 


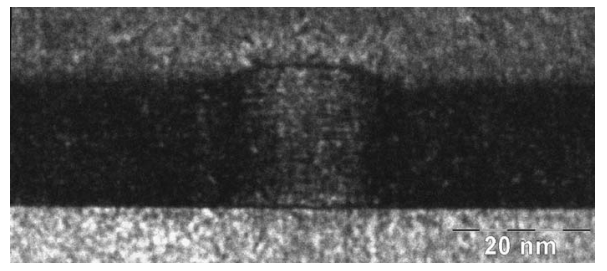

FIG. 1. Cross-sectional TEM image of the columnar dot structure along [110] direction.

the dot [Fig. 2(a)] and out of it, i.e., across the 2D layer [Fig. 2(b)]. The technical details of the TEM experiment and derivation of the layer composition have been described elsewhere. ${ }^{10,11}$

Contactless electroreflectance has been measured placing the sample in a capacitor with a semitransparent top plate allowing us to measure the normalized changes in the sample reflectivity coefficient caused by the applied ac voltage of $2 \mathrm{kV}$ (an electromodulated reflectivity spectrum). ${ }^{9}$ Both CER and photoluminescence (PL) have been measured using lock-in technique in a setup based on $0.55 \mathrm{~m}$ focal length monochromator and thermoelectrically cooled InGaAs PIN photodiode as a detector. Further details of the setups can be found in Refs. 12 and 13.

As the TEM data show, the whole structure, in fact, includes two confined systems: the columnar dots, with almost uniform In content over their height at the average level of about $30 \%$ and a 2D layer, formed by the evolution of the initial wetting layer upon the repeated deposition of InAs/GaAs layers. The latter forms a quantum well (QW) with a thickness of about $20 \mathrm{~nm}$ and average In content on the level of $16 \%$ [the dependence of the QW composition in the growth direction based on which the confinement potential can be derived is seen in Fig. 2(b)]. Figure 3 shows room temperature CER and PL spectra measured on this columnar dot structure. For the modulated reflectivity spectrum a fitting procedure has been used ${ }^{12,13}$ which allowed generation of the moduli of particular transitions. This makes the com-

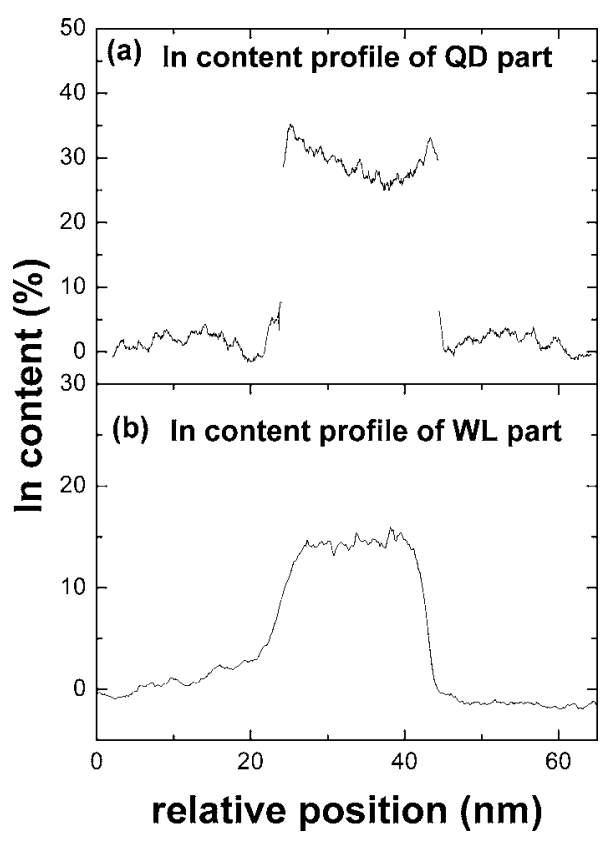

FIG. 2. (a) In content profile across the dot height. (b) In content profile out

of the dots (across the width of the WL-originating 2D layer).
Downloaded 26 Feb 2008 to 131.155.108.71. Redistribution subject to AIP license or copyright; see http://apl.aip.org/apl/copyright.jsp

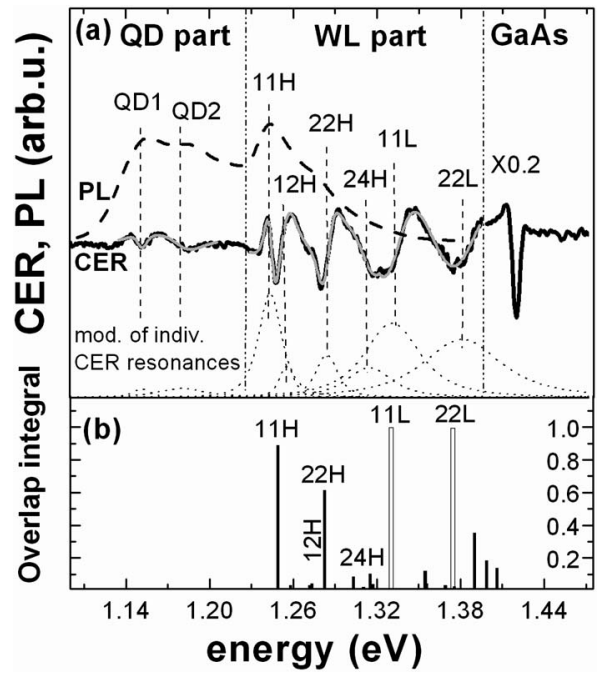

FIG. 3. (a) Room temperature CER spectra obtained for the columnar dot structures. The fits of CER features (solid gray line) together with the moduli of the individual resonances (black dotted line). PL spectra (black dashed line). (b) The calculated overlap integrals of the transitions in the region of the 2D layer InGaAs (InGaAs/GaAs quantum well) surrounding the columnar dots.

parison of the spectra simpler and enables us to observe the real confined state transition intensities (oscillator strengths). The spectra can be divided into three parts. At the energy of about $1.42 \mathrm{eV}$ a strong CER feature is observed, related to the band gap transition in the bulklike layers of the sample, which is also the barrier for the dots and the 2D layer. There are two transitions observed in both types of spectra at the low energy side, which are related to the dots. Finally, a number of CER features in the range between 1.24 and $1.4 \mathrm{eV}$ connected with the 2D layer (InGaAs/GaAs QW) are visible, a fundamental transition of which agrees with a peak in PL. The two groups of transitions can be distinguished experimentally already. First, the QD transitions are usually broader due to more inhomogeneity factors contributing to the total spectral linewidth of the ensemble (the first lowest energy transition with significantly smaller broadening indicates the ground state transition in the QW, i.e., the one at $1.24 \mathrm{eV}$ in both spectra). Second, due to fractional coverage of the surface, the QD-related features in the modulation spectra are usually much weaker than any of the 2D systems in the same sample (like those coming from the wetting layer or any other quantum wells), which makes the interpretation even easier. In order to confirm that, we have performed calculation of the QW confined state energy levels in the effective mass approximation, taking into account the potential shape exactly after the In content profile from Fig. 2(b). Further details regarding the material parameters and calculation approach exploiting the transfer matrix method can be found elsewhere. ${ }^{14-16}$ The results are presented in Fig. 3(b) in the form of bars, whose height corresponds to the intensity of the transition (its overlap integral taken between the respective envelope functions of the confined states in the valence and conduction subbands) and position to the transition energy. As it can be seen, both calculated features agree very well with those from the CER spectra (see the CER moduli). The main transitions (the strongest intensity ones) are labeled in Fig. 3(a), according to the general notation $k l H(L)$ for the transition between the $k$ th th state of the valence subband to the $l$ th state of the conduction subband for heavy to AIP license or copyright; see http://apl.aip.org/apl/copyright.jsp 
$(H)$ or light $(L)$ holes, respectively. In spite of the large number of states confined in this relatively wide well with rather complex and asymmetric potential shape, only very few of them give high oscillator strength, as clearly observed in the CER spectrum. In the second step, the two remaining lowest energy transitions need their identification. We have performed calculations assuming the dot geometry after the above-mentioned TEM data with the content profile after Fig. 2(a). We have used fully three-dimensional treatment and calculated the strain field using a linear continuum elasticity model. ${ }^{17,18}$ Next, the piezoelectric charges originating from the presence of the shear strain are calculated (with composition-dependent piezoelectric constant) and the piezoelectric potential is obtained upon solving Poisson's equation with a variable dielectric constant (which is dependent on the local composition). ${ }^{18}$ The three-dimensional Schroedinger equation has then been solved within the effective mass approximation including the following potential components: the band offsets, the above-mentioned piezoeffect related and strain-related ones via valence and conduction band deformation potentials. All the material parameters have been taken after Ref. 14. We have obtained that under these assumptions very few states are confined in such dots despite their relatively large size. This is related to the very weak in-plane confinement due to the In-containing 2D layers around the dots. Within a reasonable range of band offsets (typically 65\%-85\% for the conduction band for these contents and defined before inclusion of the strains ${ }^{14}$ ) only one electron level is always found to be confined and up to three and two levels for heavy and light holes, respectively. However, this always gives no more than two transitions with significantly high oscillator strength (the ground state heavy hole and light hole related ones), the energies of which are typically by at least $60 \mathrm{meV}$ higher than the experimental ones, which is in part related to the neglected exciton binding energy and in part to the limitations of the single band model, which has been proven to overestimate the transition energies in comparison to the eight-band $k \cdot p \cdot{ }^{19}$ In spite of that, the whole picture seems to be in reasonably good agreement with the experiment and explains the origin of the two spectral features related to the columnar QDs which have a heavy-hole-like and light-hole-like character, respectively. Unfortunately, the single band model cannot predict properly the polarization properties of these optical transitions. As it has been suggested previously for the case of similar stacked QD structures, ${ }^{7,20}$ the enhanced intensity ratio of the TM to TE-polarized edge emitted PL could be related to the valence band mixing effect (which is not present in single band approach) and significant (or even dominating) contribution of the light hole character to the ground state transitions. In order to confirm this for our columnar dots and explore further electronic structure details as, for instance, the dependence on the number of stacked layers, etc., eight-band $k \cdot p$ calculations are in progress, results of which will be the subject of an independent publication soon.
In conclusion, we have investigated the origin of the optical transitions and basics of the electronic structure for a sample with columnar InGaAs/GaAs quantum dots based on contactless electroreflectance and photoluminescence spectra and effective mass energy level calculations exploiting the structural data from TEM images. It has been obtained that the dots are surrounded by a 2D layer forming a broad quantum well with almost uniform content of approximately $16 \%$ and partly graded interfaces giving several intense optical transitions. This 2D layer, on the other hand, makes the confinement potential of the columnar dots shallow enough to confine only one electron state and a very few states for the holes, producing only two significant QD transitions in the spectra.

This work was conducted in the framework of the European FP6/017140 Project "ZODIAC." It was also supported by the Polish Ministry of Science and Higher Education within Grant No. 1 P03 B04829 and SPUB Project No. 120/ 6.PR UE/2005/7, by the Foundation for Polish Science through a Subsidy No. 8/2005, by the Swiss National Science Foundation, and the Swiss COST-OFES program.

${ }^{1}$ G. T. Liu, A. Stintz, H. Li, K. J. Malloy, and L. F. Lester, Electron. Lett. 35, 1163 (1999).

${ }^{2}$ M. V. Maksimov, N. Y. Gordeev, S. V. Zaitsev, P. S. Kop'ev, I. V. Kochnev, N. N. Ledentsov, A. V. Lunev, S. S. Ruvimov, A. V. Sakharov, A. F. Tsatsul'nikov, Y. M. Shernyakov, Z. I. Alferov, and D. Bimberg, Semiconductors 31, 124 (1997).

${ }^{3}$ M. Sugawara, H. Ebe, N. Hatori, M. Ishida, Y. Arakawa, T. Akiyama, K. Otsubo, and Y. Nakata, Phys. Rev. B 69, 235332 (2004).

${ }^{4}$ P. Yu, W. Langbein, K. Leosson, J. M. Hvam, N. N. Ledentsov, D. Bimberg, V. M. Ustinov, A. Y. Egorov, A. E. Zhukov, A. F. Tsatsulnikov, and Y. G. Mausikhin, Phys. Rev. B 60, 16680 (1999).

${ }^{5}$ T. Kita, O. Wada, H. Ebe, Y. Nakata, and M. Sugawara, Jpn. J. Appl. Phys., Part 2 41, L1143 (2002).

${ }^{6}$ T. Kita, P. Jayavel, O. Wada, H. Ebe, Y. Nakata, and M. Sugawara, Phys. Status Solidi C 4, 1137 (2003).

${ }^{7}$ T. Kita, N. Tamura, O. Wada, M. Sugawara, Y. Nakata, H. Ebe, and A. Arakawa, Appl. Phys. Lett. 88, 211106 (2006).

${ }^{8}$ L. Aigouy, T. Holden, F. H. Pollak, N. N. Ledentsov, W. M. Ustinov, P. S. Kop'ev, and D. Bimberg, Appl. Phys. Lett. 70, 3329 (1997).

${ }^{9}$ M. Motyka, R. Kudrawiec, G. Sęk, J. Misiewicz, I. L. Krestnikov, and A. Kovsh, Semicond. Sci. Technol. 21, 1402 (2006).

${ }^{10}$ G. Patriarche, L. Largeau, J. C. Harmand, and D. Gollub, Appl. Phys. Lett. 84, 203 (2004).

${ }^{11}$ A. Lemaitre, G. Patriarche, and F. Glas, Appl. Phys. Lett. 85, 3717 (2004).

${ }^{12}$ J. Misiewicz, P. Sitarek, G. Sęk, and R. Kudrawiec, Mater. Sci. (Poland) 21, 263 (2003).

${ }^{13}$ J. Misiewicz, G. Sęk, R. Kudrawiec, and P. Sitarek, Thin Solid Films 450, 14 (2004).

${ }^{14}$ I. Vurgaftman, J. R. Meyer, and L. R. Ram-Mohan, J. Appl. Phys. 89, 5815 (2001).

${ }^{15}$ B. Jonsson and S. T. Eng, IEEE J. Quantum Electron., 26, 2025 (1990).

${ }^{16}$ M. Kubisa, L. Bryja, K. Ryczko, J. Misiewicz, C. Bardot, M. Potemski, G. Ortner, M. Bayer, A. Forchel, and C. B. Sørensen, Phys. Rev. B 67, 035305 (2003).

${ }^{17}$ C. Pryor, M.-E. Pistol, and L. Samuelson, Phys. Rev. B 56, 10404 (1997).

${ }^{18}$ O. Stier, M. Grundmann, and D. Bimberg, Phys. Rev. B 59, 5688 (1999).

${ }^{19}$ C. Pryor, Phys. Rev. B 57, 7190 (1998).

${ }^{20}$ T. Saito, T. Nakaoka, T. Kakitsuka, and Y. Yoshikuni, Y. Arakawa, Physica E (Amsterdam) 26, 217 (2005). 